\title{
ORIENTASI PEMBELIAN DALAM KONGRUENSI-TERPERSEPSI PADA RITEL MULTI KANAL
}

\author{
Michael Christian \\ Manajemen, Universitas Bunda Mulia \\ Alamat surel: michaelchristianid@gmail.com
}

\begin{abstract}
:
Consumers often compare the place where they buy product based on experience. Several factors become their main consideration, such as service quality, product, and promotion offered. Perceived congruence related to the same aspects of the visit/buying experiences, is compared to more than one channels of a retailer in selling its products. Unfortunately, there are gaps in consumer's experiences which challenge retailers to establish strategy in gaining and maintaining consumers. This research aims to investigate the impact of store and website image to perceived congruence based on the buying orientation. The Structural Equation Modellng (SEM) is implemented to analyze data collected from 140 respondents having the experience in visiting Matahari store department and Mataharimall.com on the last six months. The result shows that perceived congruence is influenced by store image and website image. Further, consumer's buying orientation impacts both of the channels. Researchers are suggested to investigate the retail image to explain the impact of perceived congruence.
\end{abstract}

Keywords: outlet image, website image, perceived congruence

\begin{abstract}
Abstrak
Konsumen sering membandingkan pengalamannya dalam melakukan pembelian berdasarkan beberapa faktor seperti: kualitas layanan yang diterima, kualitas produk, dan penawaran promosi. Kongruensiterpersepsi merupakan persepsi dari pengalaman konsumen membeli di satu tempat dengan tempat lainnya berdasarkan beberapa faktor. Hal ini memungkinkan untuk terciptanya jurang pembeda persepsi, sehingga para peritel harus membuat strategi agar tetap mendapatkan dan sekaligus mempertahankan konsumen. Tujuan penelitian ini adalah untuk menginvestigasi ada tidaknya pengaruh citra outlet dan citra daring terhadap kongruensi-terpersepsi yang didasarkan pada orientasi pembelian konsumen. Penelitian ini menggunakan model Structural Equation Modellng (SEM) dengan 140 responden yang memiliki pengalaman membeli di Mataharimall.com dalam 6 bulan terakhir. Hasil dari penelitian ini menjelaskan bahwa kongruensi-terpersepsi dipengaruhi oleh citra outlet dan citra daring, dimana kedua citra tersebut juga dipengaruhi oleh orientasi pembelian konsumen. Berdasarkan penelitian ini, penelitian berikutnya disarankan dapat menjelaskan pengaruh citra ritel secara keseluruhan dengan menggunakan faktor-faktor kongruensi-terpersepsi.
\end{abstract}

Kata kunci: citra outlet, citra daring, kongruensi-terpersepsi

\section{PENDAHULUAN}

\section{Latar Belakang}

Konsumen yang memiliki pengalaman pembelian produk yang berbeda pada satu tempat dengan tempat tertentu menciptakan penilaian persepsi yang berbeda. Steve Burt and Thelander (2007) menjelaskan bahwa penilaian yang terbentuk dalam persepsi konsumen lebih mudah tercipta pada saat berada di tempat pembelian (outlet). Hal ini dapat menjelaskan lebih lanjut bahwa pengalaman akan menciptakan persepsi terhadap satu tempat dengan tempat lainnya, pada ekspektasi kepuasan dengan tingkat yang berbeda. Ekspektasi dari persepsi yang tercipta memiliki kesamaan faktor-faktor pembentuk baik satu, beberapa maupun keseluruhan faktor. Di kebanyakan ritel yang menjual produk seperti pakaian dan perangkat elektronik, konsep kesamaan persepsi yang tercipta (kongruensiterpersepsi) telah digunakan dalam beberapa pengujian (O'Cass dan Grace, 2008).

Para peritel yang memiliki lebih dari satu tempat penjualan mau tidak mau harus menghadapi persepsi yang berbeda dari konsumen. Ekspektasi konsumen pada tiap tempatnya menjadi tantangan untuk dicapai, ditambah lagi dengan keberagaman permintaan konsumen dan perkembangan 
teknologi daring yang memudahkan dalam mendapatkan produk. Hal ini juga yang menyebabkan peritel dengan konsep tempat penjualan "dua dunia" menjadi lebih menantang. Konsep outlet dan daring dewasa ini sering digunakan di dunia, salah satunya di Indonesia yaitu yang dilakukan oleh peritel Matahari. Kemungkinan untuk dibandingkan antar kedua kanal pada ritel tersebut akan sangat mudah terjadi, apalagi pada outlet dari satu ritel (San Martín Gutiérrez et al., 2010). Tidak hanya pada faktor pembentuk yang terdapat pada outlet saja, faktor-faktor pembentuk dapat tercipta secara konsep kanal daring satu ritel, mencakup situs, komunikasi dan komunitas secara daring (Broderick, 2016).

Penelitian-penelitian pada fenomena ini kebanyakan hanya berfokus pada pengukuran citra ritel pada salah satu kanal saja. Ditambah lagi belum populernya penelitian yang meneliti mengenai citra kedua kanal penjualan dari satu ritel dengan faktor orientasi konsumen dalam melakukan pembelian. Hal ini juga pernah disebutkan oleh Wang et al. (2009) tentang belum banyaknya penelitian-penelitian yang melibatkan pengukuran persepsi konsumen pada multi kanal. Ritel dengan tempat penjualan multi kanal akan memberikan pengalaman yang berbeda di tiap pembelinya yang kemungkinan juga membentuk ketidakpuasan atau risiko. Seperti yang dijelaskan oleh Bezes (2016) dalam penelitiannya bahwa akan terciptanya risiko-risiko bagi konsumen dalam melakukan pembelian baik pada outlet mau pun secara daring. Oleh karena itu, berdasarkan penjelasan-penjelasan tersebut perlu penelitian yang menjelaskan pengaruh kongruensi-terpersepsi dari citra multi kanal dari satu ritel yang dilatarbelakangi oleh orientasi pembelian konsumen.

\section{Masalah Penelitian}

Berdasarkan latar belakang diatas, maka penelitian ini memiliki beberapa masalah yaitu: (1) Apakah ada pengaruh orientasi pembelian pada konsumen terhadap citra ritel Matahari secara outlet?, (2) Apakah ada pengaruh orientasi pembelian pada konsumen terhadap citra ritel Matahari secara daring?, (3) Apakah ada pengaruh citra ritel Matahari secara outlet terhadap kongruensi-terpersepsi?, (4) Apakah ada pengaruh citra ritel Matahari secara daring terhadap kongruensi-terpersepsi?

\section{Tujuan Penelitian}

Penelitian ini memiliki beberapa tujuan. Ada pun tujuan penelitian ini adalah untuk (1) Mengetahui pengaruh orientasi pembelian konsumen terhadap citra ritel Matahari secara outlet, (2) Mengetahui pengaruh orientasi pembelian konsumen terhadap citra ritel Matahari secara daring, (3) Mengetahui pengaruh citra ritel Matahari secara outlet terhadap kongruensiterpersepsi, (4) Mengetahui citra ritel secara daring terhadap kongruensi-terpersepsi.

\section{TINJAUAN PUSTAKA}

\section{Orientasi Pembelian}

Orientasi pembelian berkaitan dengan karakter individu yang melakukan pembelian terhadap produk tertentu. Stone (1954) menyebutkan bahwa paling tidak terdapat empat kelompok dari pembeli yaitu kelompok yang mempertimbangkan nilai ekonomis suatu produk, kelompok yang membeli dengan mempertimbangkan kepentingan atau kebutuhan pembelian secara pribadi, kelompok etis, dan yang terakhir adalah kelompok apatis. Dalam proses pembelian yang dilakukan, tiap kelompok tersebut akan mempertimbangkan faktor-faktor seperti: layanan ritel yang diberikan oleh pramuniaga, harga produk yang ditawarkan, dan kualitas dari produk yang ditawarkan (Osman, 2006). Penelitian ini menggunakan faktor-faktor seperti informasi terkait tujuan nilai ekonomis produk yang dibeli (ekonomis), pertimbangan waktu yang dihabiskan dalam melakukan pembelian (etis), pembelian terencana dengan daftar yang telah dibuat, atau pembelian tidak terencana (apatis), dan kebutuhan kesenangan/hiburan (individualis).

\section{Citra Outlet}

Burt dan Davies (2010) menjelaskan bahwa faktor-faktor pembentuk citra merek suatu ritel sangat berkaian erat dengan dimensi-dimensi yang ada di dalamnya, seperti layanan yang diberikan yang berguna 
untuk capaian ekspektasi pembeli (Osman, 2006) dan kualitas dari produk yang ditawarkan yang bertujuan untuk membentuk citra yang positif (Chebat et al., 2006). Katerattanakul dan Sau (2003) menyebutkan bahwa citra pembentuk pada suatu outlet ritel dapat ditentukan oleh beberapa faktor seperti fasilitas fisik, merchandise, promosi, layanan, kepuasan pasca transaksi, kenyamanan, suasana outlet, pelanggan, dan faktor dari sisi perusahaan. Bezes (2013) menggunakan faktor-faktor seperti lokasi, tata letak, merchandise, promosi, harga, reputasi, informasi, hal yang berkaitan dengan layanan, hal yang berkaitan dengan kanal lain, dan faktor dari sisi perusahaan. Berdasarkan penjelasan tersebut maka penelitian ini menggunakan faktor kemenarikan tata letak produk, kenyamanan dalam melakukan pembelian dan daya tarik bentuk promosi yang ditawarkan.

\section{Citra Situs}

Broderick (2016) menjelaskan bahwa situs yang digunakan suatu ritel untuk tempat penjualannya lebih mempertimbangkan komunikasi yang digunakan agar dapat menciptakan hubungan yang baik dengan pelanggan. Komunikasi pemasaran yang dilakukan tidak lepas dari tingkat capaian ekspektasi pelanggan dalam pelayanan informasi yang diberikan. Kajian-kajian yang ada lebih menekankan pada faktor-faktor utama pembentuk citra situs dan faktor-faktor antiseden pembentuk lainnya (Kwon dan Lennon, 2009) sehingga untuk mengukur kongruensi-terpersepsi dilakukan dengan menggunakan faktor-faktor pembentuk yang sama pada kanal-kanal yang ada. Hal itu juga disebutkan oleh Wang et al. (2009) dimana faktor lain pembentuk persepsi yang kongruen pada kanal-kanal yang ada dapat dijadikan pembanding.

\section{Kongruensi-terpersepsi}

Telah disebutkan pada penjelasan sebelumnya bahwa pembeli diklasifikasikan ke dalam beberapa tipe yang dapat menjelaskan faktor dominan pembentuk kongruensi-terpersepsi untuk tiap konsumennya akan sangat subjektif.
Individu akan bersedia berlama-lama menghabiskan waktu pada tempat ritel tertentu apabila mendapatkan kenikmatan dalam mengeksplorasi tiap informasi dan tampilan yang ada. Situs suatu ritel akan memperhatikan disain, warna dan tampilan tiap produk yang ditawarkan untuk mendapatkan kesediaan pengunjung lebih lama lagi dalam melihat-lihat atau mencari informasi tertentu (Cho dan Kim, 2012). Kongruensi-terpersepsi secara konsep mengenal lima tingkat kesamaan untuk menjelaskan kongruensi-terpersepsi. Kelima tingkatan itu terdiri dari (1) kesamaan tingkat tertinggi, (2) kesamaan tingkat menengah, (3) kesamaan tingkat rendah, (4) kesamaan dengan tingkat tidak signifikan, dan (5) tidak memiliki kesamaan sama sekali (Osman, 2006). Faktor-faktor yang digunakan dalam penelitian ini dalam pembentuk kongruensi-terpersepsi adalah kesamaan suasana yang tercipta di kedua kanal, tiap kanal mampu mencerminkan kanal lainnya, kesamaan yang konsisten pada produk yang disediakan, kesamaan konsisten pada bentuk penawaran/promosi (Bezes, 2013).

\section{Keterkaitan Orientasi Pembelian Dengan Citra}

Osman (2006) menjelaskan bahwa orientasi memiliki keterhubungan pada citra tempat melakukan pembelian. Faktor-faktor pertimbangan pada penjelasan sebelumnya memberikan indikasi bahwa terdapat keterhubungan faktor-faktor pembelian yang terjadi pada outlet suatu ritel. Faktor-faktor akan dengan mudah memengaruhi orientasi pembelian konsumen dan juga citra outlet ritel tersebut. Oleh karena itu penelitian ini mengemukakan Hipotesis 1 (H1a: Ada pengaruh orientasi pembelian terhadap citra outlet, H1b: Ada pengaruh orientasi pembelian terhadap citra secara daring).

\section{Keterkaitan Citra Dengan Kongruensi- terpersepsi}

Baik outlet mau pun situs suatu ritel, keduanya memiliki pengaruh pada persepsi yang terbentuk di pikiran konsumen. Misalnya pada situs yang memiliki disain menarik perhatian pengunjung, akan mampu meningkatkan waktu dan pengalaman 
kunjungan (Ilsever et al., 2007). Oleh karena itu, kesamaan persepsi pada outlet dan daring dari satu ritel harus memperhatikan tingkat kesamaan tertentu sesuai dengan sasaran peritel. Penilaian-penilaian pada faktor-faktor terkait di dalamnya seperti layanan dan produk akan menjadi prioritas konsumen (Cowart et al., 2008) yang pada akhirnya akan menjadi penentu keputusan pembelian (Ibrahim dan Najjar, 2008). Faktor pembentuk lain yang dapat tidak kalah penting adalah rich sensory design yang mencakup pengalaman dengan tujuan hiburan dan estetika (Jeong et al., 2009). Berdasarkan penjelasan di atas, penelitian ini mengemukakan Hipotesis 2 (H2: Ada pengaruh citra outlet terhadap kongruensi-terpersepsi) dan Hipotesis 3 (H3:Ada pengaruh citra secara daring terhadap kongruensi-terpersepsi).

\section{METODE PENELITIAN}

Penelitian ini menggunakan teknik penelitian kuantitatif dengan menggunakan kuesioner pada skala Likert (1-5) sebagai instrumen dan diolah dengan Partial Least Square (PLS) 3.0. Responden dalam penelitian ini merupakan individu yang pernah mengunjungi kedua kanal yang dimaksud dalam penelitian ini dalam enam bulan terakhir. Jumlah responden yang digunakan dalam penelitian ini diambil secara purposive sebanyak 140 responden dimana jumlah tersebut diperoleh dari hasil jumlah indikator dikali 10 (Hair et al., 2011). Model penelitian yang digunakan dijelaskan pada gambar 1.

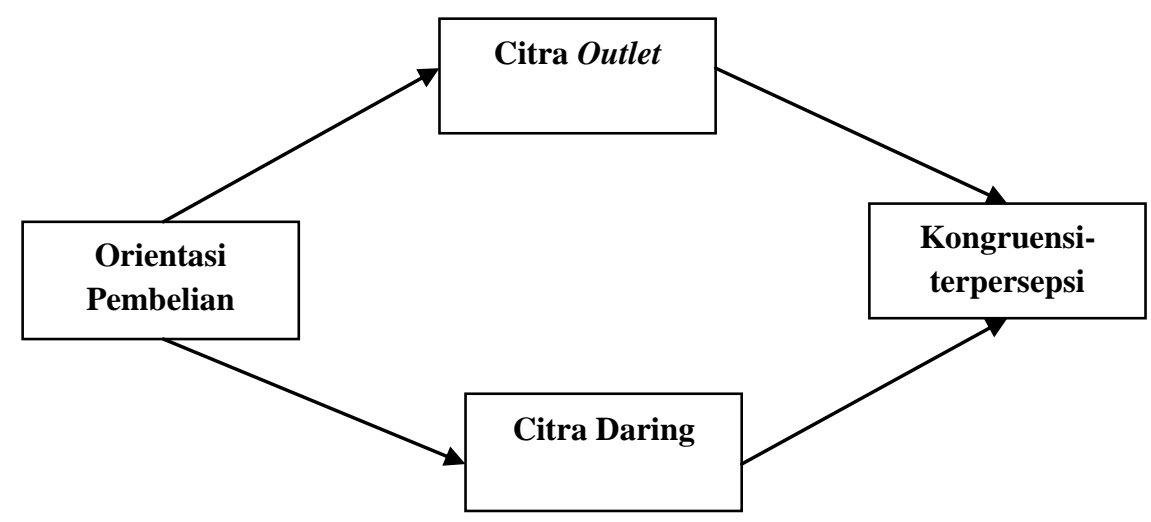

Sumber: Bezes (2016), Osman (2006)

Gambar 1. Model penelitian

\section{HASIL DAN PEMBAHASAN}

\section{Deskripsi Profil Responden Penelitian}

Tabel 1 menjelaskan bahwa mayoritas responden dalam penelitian ini adalah kelompok respoden yang berusia muda (di bawah 20 tahun) yaitu sebesar 46,43\%. Sejalan dengan kelompok usia, status responden secara dominan juga berasal dari kelompok muda yaitu dengan status mahasiswa/sederajat dengan jumlah sebesar 70\%. Hal ini mampu menjelaskan bahwa penggunaan konsep pembelian multi kanal khususnya secara daring menjadi prioritas kelompok usia muda yang salah satu karakternya adalah dekat dengan hal-hal yang berkaitan dengan hal-hal praktis dan teknologi daring. Gender dalam penelitian ini menjelaskan juga stereotype bahwa kelompok wanita lebih memiliki keinginan dalam melakukan pembelian produk dapat dijelaskan melalui hasil penelitian ini. 
Tabel 1. Deskripsi Profil Respoden Penelitian

\begin{tabular}{|c|c|c|c|}
\hline Deskripsi & Keterangan & Jumlah & $\%$ \\
\hline \multirow{2}{*}{ Gender } & Laki-laki & 68 & $48,57 \%$ \\
\hline & Perempuan & 72 & $51,43 \%$ \\
\hline \multirow{5}{*}{ Usia } & Di bawah 20 tahun & 82 & $46,43 \%$ \\
\hline & $20-25$ tahun & 36 & 26,43 \\
\hline & 26-30 tahun & 11 & 12,14 \\
\hline & $31-35$ tahun & 7 & $8,57 \%$ \\
\hline & $36-40$ tahun & 4 & $6,43 \%$ \\
\hline \multirow{3}{*}{ Status } & Mahasiswa/sederajat & 112 & $70,00 \%$ \\
\hline & Karyawan & 21 & $22,14 \%$ \\
\hline & Wirausaha & 7 & $7,86 \%$ \\
\hline
\end{tabular}

Sumber: Hasil Pengolahan, $(\mathrm{n}=140)$

\section{Uji Kesahihan}

Semua indikator konstruk dapat dinyatakan sahih dimana pada tabel outer loading menunjukkan angka di atas 0,70. Kesahihan juga dapat dilihat dari tabel
Average Varian Extracted (AVE) yang menunjukkan semua indikator-indikator dari peubah memiliki angka di atas 0,5 (Ghozali dan Latan, 2015).

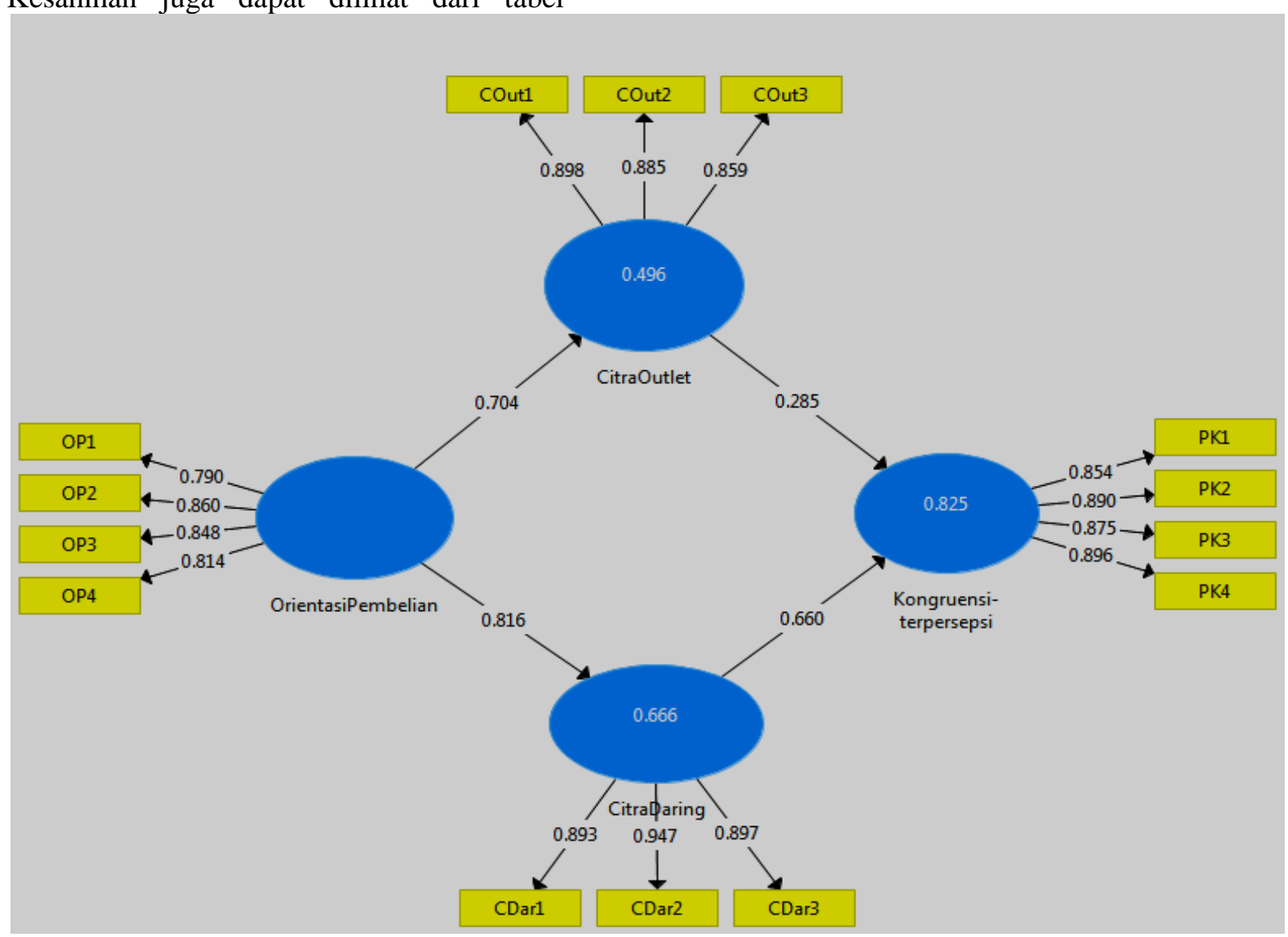

Sumber: Hasil Pengolahan SMART PLS 3.0, $(\mathrm{n}=140)$

Gambar 2. Model PLS-Algorithm 
Tabel 2. Outer Loading

\begin{tabular}{lcccc} 
& $\begin{array}{c}\text { CitraDaring } \\
\text { CDar1 }\end{array}$ & CitraOutlet & Orientasi Pembelian & $\begin{array}{c}\text { Kongruensi- } \\
\text { terpersepsi }\end{array}$ \\
\hline CDar2 & 0,947 & & \\
\hline CDar3 & 0,897 & & & \\
\hline COut1 & & & \\
\hline COut2 & 0,898 & & \\
\hline COut3 & 0,885 & & \\
\hline OP1 & 0,859 & 0,790 & 0,854 \\
\hline OP2 & & 0,860 & 0,890 \\
\hline OP3 & 0,848 & 0,875 \\
\hline OP4 & & 0,814 & 0,896 \\
\hline PK1 & & & \\
\hline PK2 & & & \\
\hline PK3 & & & \\
\hline
\end{tabular}

Sumber: Hasil Pengolahan SMART PLS 3.0, $(\mathrm{n}=140)$

Tabel 3. Average Variance Extracted (AVE)

\begin{tabular}{lc} 
& A VE \\
\hline Citra Daring & 0,833 \\
\hline Citra Outlet & 0,775 \\
\hline Orientasi Pembelian & 0,686 \\
\hline Kongruensi-terpersepsi & 0,772 \\
\hline
\end{tabular}

Sumber: Hasil Pengolahan SMART PLS 3.0, $(\mathrm{n}=140)$

\section{Uji Kehandalan}

Dalam melakukan pengukuran kehandalan suatu konstruk dengan indikator reflektif dapat dilakukan dengan melihat angka pada Cronbach's Alpha dan
Composite Reliability yang harus di atas 0,70 (Ghozali dan Latan, 2015). Dalam hal ini hasil olahan dapat dinyatakan handal karena indikator-indikator dari semua peubah memenuhi angka yang ditentukan.

Tabel 4. Cronbach's Alpha \& Compoosite Reliability

\begin{tabular}{lcc} 
& Cronbach's Alpha & Composite Reliability \\
Citra Daring & 0,869 & 0,937 \\
\hline Citra Outlet & 0,833 & 0,912 \\
\hline Orientasi Pembelian & 0,831 & 0,897 \\
\hline Kongruensi-terpersepsi & 0,896 & 0,931 \\
\hline
\end{tabular}

Sumber: Hasil Pengolahan SMART PLS 3.0, $(\mathrm{n}=140)$

\section{Kesesuaian Model Struktural}

Tabel $R$ Square menjelaskan bahwa orientasi pembelian dapat menjelaskan perubahan citra daring sebesar $66,6 \%$. Orientasi pembelian dapat menjelaskan perubahan citra outlet sebesar 49,6\%. Citra daring dan citra outlet menjelaskan perubahan kongruensi-terpersepsi sebesar $82,5 \%$. 
Tabel 5. R-Square

\begin{tabular}{lr} 
& $\boldsymbol{R}$-Square \\
Citra Daring & 0,666 \\
\hline Citra Outlet & 0,496 \\
\hline Kongruensi-terpersepsi & 0,825 \\
\hline
\end{tabular}

Sumber: Hasil Pengolahan SMART PLS 3.0, $(\mathrm{n}=140)$

\section{Uji Signifikansi}

Pada tabel di bawah dapat dijelaskan bahwa semua konstruk memiliki korelasi satu dengan yang lainnya, karena berada di atas 1,96 pada $t$ statistic. Citra outlet dipengaruhi oleh orientasi pembelian konsumen (H1a) begitu juga dengan citra ritel secara daring dipengaruhi oleh faktor yang sama yaitu orientasi pembelian (H1b). Kongruensi-terpersepsi dipengaruhi oleh citra outlet $(\mathrm{H} 2)$ dan citra ritel secara daring (H3).

Tabel 6. Outer Loading

\begin{tabular}{lcc} 
& $\begin{array}{c}\text { T Statistic } \\
(\mid \text { STDEV } \mid)\end{array}$ & $\boldsymbol{p}$ values \\
\hline CitraDaring $\rightarrow$ CDar1 & 41,398 & 0,000 \\
\hline CitraDaring $\rightarrow$ CDar2 & 95,502 & 0,000 \\
\hline CitraDaring $\rightarrow$ CDar3 & 54,025 & 0,000 \\
\hline CitraOutlet $\rightarrow$ COut1 & 38,804 & 0,000 \\
\hline CitraOutlet $\rightarrow$ COut2 & 45,618 & 0,000 \\
\hline CitraOutlet $\rightarrow$ COut3 & 40,095 & 0,000 \\
\hline Orientasi Pembelian $\rightarrow$ OP1 & 21,513 & 0,000 \\
\hline Orientasi Pembelian $\rightarrow$ OP2 & 34,210 & 0,000 \\
\hline Orientasi Pembelian $\rightarrow$ OP3 & 42,954 & 0,000 \\
\hline Orientasi Pembelian $\rightarrow$ OP4 & 25,622 & 0,000 \\
\hline Kongruensi-terpersepsi $\rightarrow$ PK1 & 28,470 & 0,000 \\
\hline Kongruensi-terpersepsi $\rightarrow$ PK2 & 41,197 & 0,000 \\
\hline Kongruensi-terpersepsi $\rightarrow$ PK3 & 36,170 & 0,000 \\
\hline Kongruensi-terpersepsi $\rightarrow$ PK4 & 54,452 & 0,000 \\
\hline
\end{tabular}

Sumber: Hasil Pengolahan SMART PLS 3.0, $(\mathrm{n}=140)$

Tabel 7. Path Coefficient

\begin{tabular}{|c|c|c|}
\hline & $\begin{array}{l}\text { T Statistic } \\
\text { (|STDEV|) }\end{array}$ & $p$ values \\
\hline $\begin{array}{l}\text { CitraDaring } \rightarrow \text { Kongruensi- } \\
\text { terpersepsi }\end{array}$ & 10,947 & 0,000 \\
\hline $\begin{array}{l}\text { CitraOutlet } \rightarrow \text { Kongruensi- } \\
\text { terpersepsi }\end{array}$ & 4,067 & 0,000 \\
\hline $\begin{array}{l}\text { Orientasi Pembelian } \rightarrow \\
\text { CitraDaring }\end{array}$ & 22,380 & 0,000 \\
\hline OrientasiPembelian $\rightarrow$ CitraOutlet & 14,483 & 0,000 \\
\hline
\end{tabular}


Pada hipotesis 1a dan hipotesis $1 \mathrm{~b}$, pengaruh orientasi pembelian terhadap citra outlet dan citra secara daring, dalam model penelitian ini sejalan dengan penelitian yang dilakukan oleh Osman (2006). Selanjutnya dalam menjelaskan hipotesis 2 dan hipotesis 3 , penelitian ini sejalan dengan penelitian yang dilakukan oleh Bezes (2013) dimana ada pengaruh pada kedua kanal pada satu ritel terhadap kongruensi-terpersepsi.

\section{SIMPULAN DAN SARAN}

\section{Simpulan}

Berdasarkan hasil penelitian dapat disimpulkan bahwa secara keseluruhan kongruensi-terpersepsi ritel dengan konsep multi kanal dipengaruhi oleh citra tiap kanal dan juga karakter orientasi pembeli ritel. Matahari dalam penelitian ini mampu membentuk kongruensi-terpersepsi dari kedua kanalnya. Faktor-faktor yang ada di outlet dan situs Matahari mampu membentuk kongruensi-terpersepsi. Disimpulkan juga bahwa Matahari dalam penelitian ini mampu menempatkan karakter orientasi pembeli di kedua kanalnya.

\section{Saran}

Hasil penelitian menunjukkan bahwa kongruensi-terpersepsi pada ritel yang disebabkan oleh citra ritel pada outlet memiliki angka yang lebih kecil dibandingkan dengan faktor citra konsumen terhadap ritel secara daring. Disarankan bahwa ritel tersebut harus meningkatkan faktor daya tarik pembanding, seperti daya tarik kualitas layanan yang diberikan oleh pramuniaga agar dapat lebih responsif seperti layanan secara daring; tampilan produk khususnya yang berkaitan dengan bentuk promosi, potongan harga dan produk baru ditata sama menariknya dengan yang disajikan secara daring. Hal tersebut akan sangat membantu dalam menciptakan persepsi yang kongruen di pikiran konsumen di kedua kanal dari ritel tersebut. Selanjutnya disarankan untuk penelitian berikutnya dapat menggunakan faktor tambahan seperti citra merek ritel secara keseluruhan. Kongruensi-terpersepsi sebagai hasil dari kedua kanal suatu ritel seberapa dapat menjelaskan pengaruhnya pada citra merek ritel secara keseluruhan.

\section{DAFTAR PUSTAKA}

Bezes, C. 2013. Effect Of Channel Congruence On A Retailer's Image. International Journal of Retail \& Distribution Management, 41, 254273.

Bezes, C. 2016. Comparing Online And InStore Risks In Multichannel Shopping. International Journal of Retail \& Distribution Management, 44.

Broderick, C. D. A. J. 2016. Engaging Customers During A Website Visit: A Model Of Website Customer Engagement. International Journal Of Retail \& Distribution Management, 44, 1-37.

Burt, S. L. \& Davies, K. 2010. From The Retail Brand To The Retail-Er As A Brand: Themes And Issues In Retail Branding Research International Journal Of Retail \& Distribution Management, 38, 865-878.

Chebat, J.-C., Sirgy, M. J. \& St-James, V. 2006. Upscale Image Transfer From Malls To Stores: A Self-Image Congruence Explanation. Journal of Business Research, 59, 1288-1296.

Cho, E. \& Kim, Y.-K. 2012. The Effects Of Website Designs, Self-Congruity, And Flow On Behavioral Intention. International Journal of Design, 6, 31-39.

Cowart, K. O., Fox, G. L. \& Wilson, A. E. 2008. A Structural Look At Consumer Innovativeness And SelfCongruence In New Product Purchases. Psychology \& Marketing, 25, 1111-1130.

Ghozali, I. \& Latan, H. 2015. Partial Least Square : Konsep, Teknik, Dan Apilikasi Menggunakan Program Smartpls 3.0, Semarang, Badan Penerbit Universitas Diponegoro.

Hair, J., Black, W., Babin, B. \& Anderson, R. 2011. Multivariate Data Analysis, New Jersey. 
Ibrahim, H. \& Najjar, F. 2008. Assessing The Effects Of Self-Congruity, Attitudes And Customer Satisfaction On Customer Behavioral Intenions In Retail Environment. Marketing Intelligence \& Planning, 26, 207227.

Ilsever, J., Cyr, D. \& Parent, M. 2007. Extending Models Of Flow And ELoyalty. Journal of Information Science And Technology, 4, 3-22.

Jeong, S. W., Fiore, A. M., Niehm, L. S. \& \& Lorenz, F. O. 2009. The Role Of Experiential Value In Online Shopping: The Impacts Of Product Presentation On Sonsumer Responses Towards An Apparel Web Site. Internet Research, 19, 105-124.

Katerattanakul, P. \& Sau, K. 2003. Creating A Virtual Store Image. Communications of The Acm, 46, 226-232.

Kwon, W.-S. \& Lennon, Sharon J 2009. Reciprocal Effects Between Multichannel Retailers' Offline And Online Brand Images. Journal Of Retailing, 85, 376-390.

O'cass, A. \& Grace 2008. Understanding The Role Of Retail Store Service In Light Of Self-Image-Store Image Congruence. Psychology \& Marketing, 25, 521-537.
Osman, M. Z. 2006. A Conceptual Model Of Retail Image Influences On Loyalty Patronage Behaviour. The International Review of Retail, Distribution And Consumer Research, 3, 133-148.

San Martín Gutiérrez, S., Camarero Izquierdo, C. \& San José Cabezudo, R. 2010. Product And ChannelRelated Risk And Involvement In Online Contexts. Electronic Commerce Research And Applications,, 9, 263-273.

Steve Burt, U. J. \& Thelander, A. 2007. Retail Image As Seen Through Consumers' Eyes: Studying International Retail Image Through Consumer Photographs Of Stores. The International Review Of Retail, Distribution And Consumer Research, 17, 447-467.

Stone, G. P. 1954. City Shoppers And Urban Identification: Observations On The Social Psychology Of City Life'. The American Journal Of Sociology, $60,36-45$.

Wang, S., Beatty, S. E. \& Mothersbaugh, D. L. 2009. Congruity's Role In Website Attitude Formation. Journal Of Business Research, 62, 609-615. 